\title{
POTENTIAL PROTECTIVE EFFECTS OF ANGIOTENSIN II TYPE 1 RECEPTOR BLOCKADE IN ALZHEIMER RAT MODEL
}

\author{
Atef M. Abood ${ }^{1,2}$
}

\begin{abstract}
Physiology Department, Faculty of Medicine, King Abdulaziz University, Jeddah, Saudi Arabia ${ }^{1}$ Physiology Department, Faculty of Medicine, Ain Shams University, Cairo, Egypt $^{2}$.

Corresponding author:

Atef M. Abood

Mobile: 01114327979

E mail:

atefmabood@yahoo.com

Received: 3/4/2019

Accepted:1 6/4/2019
\end{abstract}

ABSTRACT

Background: Alzheimer disease (AD) and Alzheimer type dementia (ATD) represent major health problem in aged population. $A D$ is characterized by memory impairment, exaggerated oxidative stress and decrease antioxidant capacity. Angiotensin II and angiotensin II type 1 and type 2 receptors $\left(A T R_{1}\right.$ and $\left.A T R_{2}\right)$ are incriminated in the pathogenesis of $A D$.

Aim of the work: This study was carried out to investigate the effect of angiotensin II type 1 receptor blockade on memory function in AlCl3-induced Alzheimer in rats.

Materials and methods: Thirty animals in this study were divided into five equal groups. Group1: control rats. Group II: Alzheimer model, the rats were intraperitoneally injected with $40 \mathrm{mg} /$ kilogram body AlCl3 for 4 weeks group III: ATR 1 blocker-treated AD-group: animals were injected telmisartan in a dose of $1 \mathrm{mg} / \mathrm{kg}$. by oral gavage for 8 weeks and for the last 4 weeks were injected AlCl3. Group 4: Donepezil-treated AD-group: rats were given Donepezil $5 \mathrm{mg} / \mathrm{kg}$ orally for 8 weeks and for the last 4 weeks were injected AlCl3. Group 5: $A T R_{1}$ blocker-donepezil treated $A D$ group. After the 8 weeks, animals were suspected to short term memory testing using the Novel Object Recognition test interpreting the discrimination index (DI), Recognition index (RI), frequency of exploration and locomotor activity. Malondialdehyde (MDA), Glutathione (GSH) and glutamate contents of cerebral cortex and hippocampus homogenates were biochemically assayed.

Results: $\mathrm{AlCl}_{3}$-treated group showed impaired short-term memory indices and locomotor activity with increased MDA and decreased GSH as well as glutamate content in cerebral cortex and hippocampus. ATR $R_{1}$ blocker-treated group showed significant improvement in memory function, decreased MDA and increased GSH as well as decreased glutamate content. In $A T R_{1}$ blocker plus donepezil -treated group the effects of both drugs were additive and parallel.

Conclusion: $A T R_{1}$ blockade improved memory function in ATD induced by $\mathrm{AlCl}_{3}$ injection in rats and exerts antioxidant and antiexcitotoxic effects.

Key words Alzheimer disease - Memory function - Angiotensin II type one receptors (ATR1) - Telmisartan.

\section{INTRODUCTION:}

$\mathrm{AD}$ is a very common cause of dementia. Alzheimer type dementia (ATD) represents more than $50 \%$ of causes of dementia. Memory loss with insidious onset and progressive course represents the early manifestations of ATD $^{(1)}$. Multiple pathologic mechanisms are underlying AD. 
Enhanced oxidative stress and accumulation of reactive oxygen species (ROS) molecules feature the $\mathrm{AD}^{(2)}$. ROS molecules have been shown to enhance $A$ beta amyloid $(A \beta)$ generation, misfolding, and aggregation ${ }^{(3)}$, overwhelming lipid peroxidation ${ }^{(4)}$, as well as decline in antioxidant mechanisms ${ }^{(5)}$. The brain neurotransmitter systems are also disturbed in cases of memory impairment and ATD. Glutaminergic, serotonergic in addition to the well settled cholinergic transmitters are modulated ${ }^{(6)}$.

Angiotensin II, the main biologically active peptide of the Renin Angiotensin system (RAS) and its receptors have been identified in many brain regions including the cortex and hippocampus ${ }^{(7)}$. Several studies have been conducted to evaluate the role of ang II and its receptors in brain cognitive functions. Although a positive effect of ang II on memory function was reported earlier ${ }^{(8)}$, a negative effect of angiotensin II on memory reported later in a more detailed study by Tota et al., ${ }^{(9)}$. A lot of work about the effect of RAS system on memory function have been extrapolated through studies on angiotensin II receptors. It was suggested that a direct $\mathrm{ATR}_{2}$ receptor agonist, enhances cognitive function $^{(10)}$. Moreover, the $\mathrm{ATR}_{1}$, losartan exerted potent preventive and restorative effects on AD hallmarks, possibly by mitigating AT1-initiated oxidative stress and normalizing memory-related AT4 receptors $^{(11)}$.

When the Ang II is infused into the hippocampus, it produced a dose dependent amnesic effect with inhibitory avoidance task in rats ${ }^{(12)}$. Furthermore, administration of Ang II disrupted retrieval of aversive memory in the inhibitory avoidance task ${ }^{(13)}$.

The exaggerated activity of the brain RAS in neurodegenerative diseases ${ }^{(14)}$ and $\mathrm{AD}^{(15 \& 16)}$, makes the RAS system and its receptors an important target in researches about AD.

\section{AIM OF THE WORK:}

The aim of this study is to investigate the effect of angiotensin II type 1 receptors blockade on the memory function in a rat model of Alzheimer induced by $\mathrm{AlCl} 3$ injection.

\section{MATERIALS AND METHODS:}

Animals:

This study was carried out on 30 male Wistar rats 5-6 months old (200-250 gm body weight). Animals were kept under standard conditions of boarding in cages of 5 rats each. The rats were allowed free access to water and ad libitum feeding except before drug administration. The study was approved by ethical committee of KAU (199-311). It conforms to the NIH guidelines for the care of use of laboratory animals.

\section{Experimental protocol:}

Animals in this study were divided into 5 groups 6 rats each. Group 1: control rats; Group II: Alzheimer model (AD), the rats in this group were injected by the $0.5 \%$ methylcellulose in the first 4 weeks and then injected $\mathrm{AlCl} 3$ (Sigma Aldrich UK) dissolved in saline and given as IP injection in a dose of $40 \mathrm{mg} / \mathrm{Kg}$ body weight for another 4 weeks $^{(17-19)}$. Group III: ATR $_{1}$ blocker-treated group: animals in this group were injected telmisartan (Boehringer Ingelheim) $1 \mathrm{mg}$ was dissolved in $0.5 \%$ methylcellulose at a concentration of $1 \mathrm{mg} / 1 \mathrm{ml}$, the drug was then given in a dose of $1 \mathrm{mg} / \mathrm{kg}$. by oral gavage for 8 weeks the first 4 weeks given the $\mathrm{ATR}_{1}$ blocker plus saline and the next 4 weeks were given $\mathrm{ATR}_{1}$ blocker plus $\mathrm{AlCl} 3$ in a similar manner to group II.

The dose of $1 \mathrm{mg}$ of this blocker were chosen on basis of optimal action as it is considered normotensive and so does not affect the cerebral blood flow ${ }^{(20)}$. Group 4: 
Donepezil-treated AD group, rats were given the cholinomimetic agent Donepezil 5 $\mathrm{mg} / \mathrm{kg}$ orally ${ }^{(9)}$. for 8 weeks the first 4 weeks given the donepezil plus saline and the next 4 weeks were given donepezil plus $\mathrm{AlCl} 3$ Group 5: Alzheimer ATR 1 blocker donepezil-treated AD group, the animals were injected by both $\mathrm{ATR}_{1}$ blocker and

Table 1: The experimental protocol of this study. donepezil by the same dose and route of group 3 and 4 for 8 weeks. The first 4 weeks were injected by saline and the next 4 weeks were additionally injected by $\mathrm{AlCl} 3$. All groups are injected by the vehicle in the same dose and route of administration. The experimental protocol is shown in table1.

\begin{tabular}{|c|c|c|}
\hline Group & First 4 weeks & Next 4 weeks \\
\hline I (control) & Vehicle & vehicle \\
\hline II (Alzheimer model) & Vehicle & $40 \mathrm{mg} / \mathrm{kg} \mathrm{AlCl}{ }_{3}$ \\
\hline III $\left(\mathrm{ATR}_{1}\right.$ blocker- AD) & $\mathrm{ATR}_{1}$ blocker (telmisartan) & $\begin{array}{l}1 \mathrm{mg} / \mathrm{kg} \text { ATR1 blocker (telmisartan) }+ \\
\mathrm{AlCl}_{3}\end{array}$ \\
\hline IV (Donepezil-treated AD) & Donepezil & Donepezil $+\mathrm{AlCl}_{3}$ \\
\hline $\mathrm{V}\left(\mathrm{ATR}_{1}+\right.$ donepezil-treated $\left.\mathrm{AD}\right)$ & $\begin{array}{l}\text { Donepezil }+\mathrm{ATR}_{1} \text { blocker } \\
\text { (telmisartan) }\end{array}$ & $\begin{array}{l}\text { Donepezil }+\mathrm{ATR}_{1} \text { blocker (telmisartan) } \\
+\mathrm{AlCl}_{3}\end{array}$ \\
\hline
\end{tabular}

Assessment of short term memoty by novel object recognition test (NOR):

The NOR test is largely accepted as an indicative test for memory impairment ${ }^{(21)}$. The test was performed in sound insulated room and the objects used for recognition should have criteria specified before to be attractable and easily cleaned as well as odorless. Two identical objects are placed in the arena and rats were allowed to explore both objects for 3 minutes 15 minutes later one of the familiar objects were replaced by a new one ${ }^{(22)}$. Animals were given another 3 minutes to explore and the results were recorded regarding the following:

Frequency of exploration within the 3minute period for both the new and old objects.

The time of exploration of the familiar (TF) and of the novel object (TN).

The DI: discrimination index: was calculated as follows: $\mathrm{DI}=\mathrm{TN}-\mathrm{TF} / \mathrm{TN}+\mathrm{TF}$. The positive values for DI indicate a longer time for the exploration of new objects while negative values indicate a longer time for exploring the familiar objects which reflects memory impairment.

Distance moved by the animal during the 3-minute period $^{(22-24)}$.
Another measure of the object recognition task is $\mathrm{R}$ (recognition) index which is the time spent to explore the novel object relative to the both objects exploration time and calculated as $\mathrm{R}=\mathrm{TN} /$ TNTF $^{(24)}$.

All rats were submitted to two habituation sessions, with a 1-h interval, whereby they were allowed exploration of the apparatus 3 minutes for each session. The test sessions began 24 hours later.

Ethovision XT8A a video tracking system was used to automatically record the results and calculate the different parameters. The vision XT8A, also, records the total distance moved in centimeters and the frequency and duration of the nose point sniffing the familiar and novel objects.

\section{Brain tissue preparation:}

After the behavioral test, the rats were gently decapitated following the guidelines and regulation of KAU ethical unit. After dissection, their whole brains were removed carefully and washed in saline and divided in a sagittal plane into two halves. The Hippocampus and prefrontal cortex were dissected and immediately deep-frozen in hexane and dried ice and maintained in $-80 \circ \mathrm{C}$ for tissue homogenate assays. 
The glutamate, malondialdehyde (MDA), and glutathione (GSH) levels were estimated in their homogenates by quantification ELIZA kits (Abcam; Cambridge, UK) following the company's recommended protocol ${ }^{(25)}$.

Statistical analysis:

Data were expressed as mean \pm SEM. The Student's t-test for paired and unpaired data was performed to assess them as statistically significant intragroup and intergroup differences, respectively. All statistical data and statistical significance were analyzed using the Statistical Package for Social Sciences (SPSS Inc., Chicago, Illinois, USA), version 16. A P value less than 0.05 was considered statistically significant.

\section{RESULTS:}

Results of NOR test and motor activity (figures 1-3) and table 2:
In the figure 1 and 2, the Alzheimer model group showed significant deteriorateion of memory parameters of NOR test. DI was significantly lower in $\mathrm{AlCl} 3$ treated group $(-0.11 \pm 0.04)$; as compared to control group $0.31 \pm 0.11 \mathrm{P}<0.001)$. Similarly, The $\mathrm{R}$ index was also significantly reduced in $\mathrm{AlCl} 3$ treated group $(0.44 \pm 0.02)$ compared to non-treated control $(0.66 \pm 0.06 \mathrm{P}<0.01)$.

$\mathrm{ATR}_{1}$-treated group showed significant increase in the DI $(0.18 \pm 0.06)$ and RI $(0.59$ $\pm 0.03)$ as compared to Alzheimer nontreated group $(-0.11 \pm 0.04$ and $0.44 \pm 0.02$ respectively $\mathrm{P}<0.05)$. Similar elevation in DI and RI were found in Donepezil treated group $(0.20 \pm 0.09$ and $0.60 \pm 0.05$ respectively $\mathrm{P}<<0.01$ ). DI and RI were also significantly elevated in animals treated with both ATR $_{1}$ blocker and donepezil $(0.25 \pm$ 0.09 and 0.630 .05 respectively $\mathrm{P}<0.0001$ ).

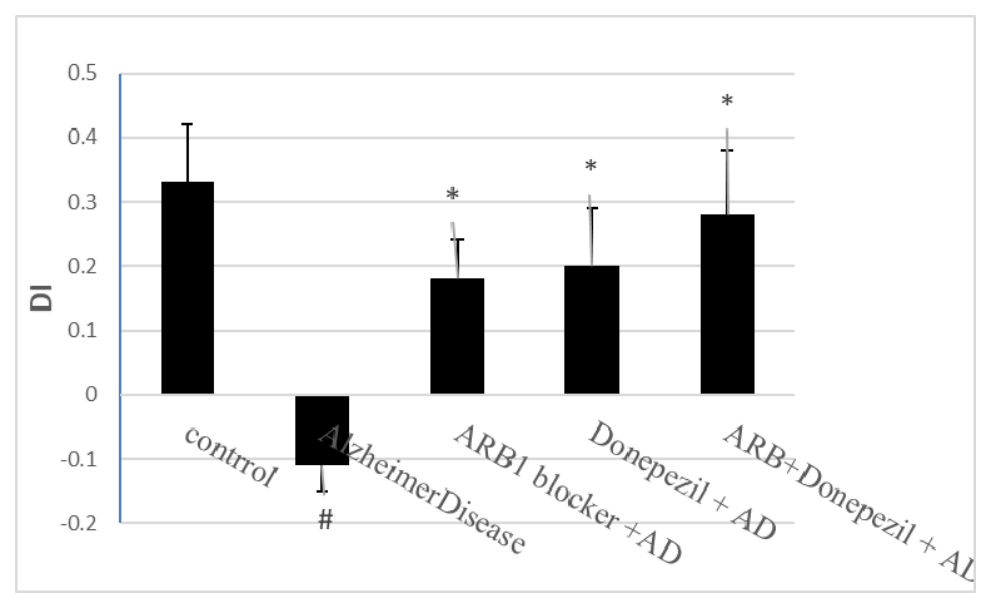

Figure (1) NOR test results. The means and standard deviations (SD) of the difficulty index of the studied groups. " significant from the control group for unpaired data $\mathrm{P}<0.05$. * significant from $\mathrm{AD}$ group for unpaired data. 


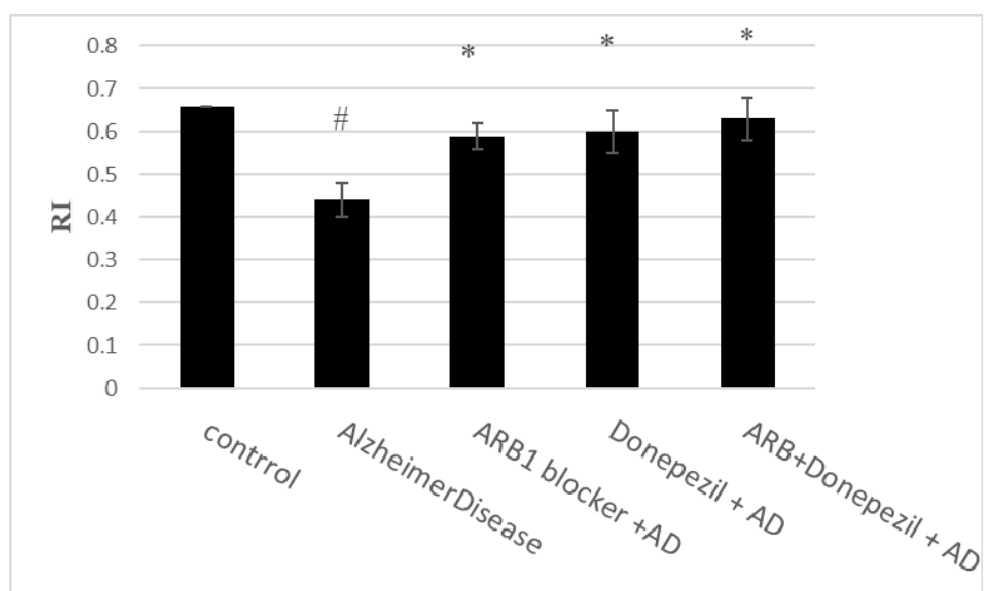

Figure (2) NOR test results: The means and standard deviations (SD) of the Recognition Index (RI) of the studied groups. " significant from the control group for unpaired data $\mathrm{P}<0.05$. *significant from $\mathrm{AD}$ group for unpaired data.

In table 2, the control group, the frequency of exploration (F) of the new object was significantly higher in control group (10.21.47 as compare to familiar object $(5.17 \pm 1.17, \mathrm{P}<0.01$. This statistical pattern was lost in $\mathrm{AlCl} 3$ treated group $9 \pm$ 1.41 vs $8.17 \pm 1.17$ for new and old objectives respectively. Although the frequency of exploration in Alzheimer group treated with $\mathrm{ATR}_{1}$ blocker was higher for new object compared to old one the elevation was not statistically significant $8.17 \pm 1.47$ vs $7.33 \pm 1.03$ respectively. Statistical results as regard frequency of exploration were significantly higher for new objects vs old one in Donepezil treated Alzheimer model $9.33 \pm 1.21$ of new object vs $5.5 \pm 1.05$ as well as in $\mathrm{ATR}_{1}$ blocker and donepezil treated animals $9.83 \pm 0.75$ vs $5.83 \pm 1.17 \mathrm{P}<0.0001$.

Table 2: The means and standard deviations (SD) of Frequency of exploration (F) of novel and familiar objects in the studied groups. *significance difference of frequency of exploration of novel and familiar objects. $\mathrm{P}<0.05$.

\begin{tabular}{|l|l|l|}
\hline Group & F for novel object & F for familiar object \\
\hline Control & $5.17 \pm 1.17$ & $10.2 \pm 1.47^{*}$ \\
\hline AD & $10.2 \pm 1.43$ & $8.17 \pm 1.17$ \\
\hline ATR1-treated AD & $8.17 \pm 1.47$ & $7.33 \pm 1.03$ \\
\hline Donepezil-treated AD & $9.33 \pm 1.21$ & $5.5 \pm 1.05^{*}$ \\
\hline ATR1 and Donepezil-treated AD & $9.83 \pm 0.76$ & $5.83 \pm 1.17^{*}$ \\
\hline
\end{tabular}

As regard the total distance moved by the animals in the 5- minute duration test, Figure 3 showed that the total distance was significantly reduced in the $\mathrm{AlCl}_{3}$ treated group compared with control group $578 \pm$ 847. vs $860 \pm 86 \quad \mathrm{P}<0.0001$. On administration of ATR1 blocker no significant changes in the distance moved compared to AD group. However, donepezil group (Mean \pm SD:796 $\mathrm{v}^{+}$85) or $\mathrm{ATR}_{1}+$ donepezil group (Mean $\pm \mathrm{SD}: 833 \pm$ 70) shows significant increase in the distance moved as compared to $\mathrm{AD}$ group (Mean \pm SD:578 \pm 84) $\mathrm{P}<0.001$ for both groups. 


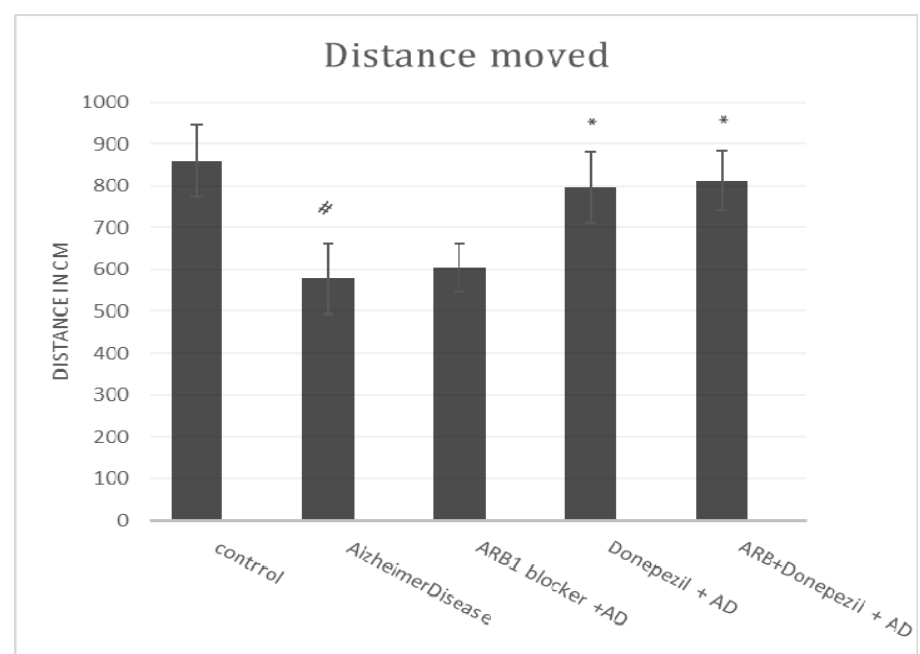

Figure (3) NOR test results. The means and standard deviations (SD) of the distance moved by the animals during the sessions of the studied groups. " significant from the control group for unpaired data $\mathrm{P}<0.05$. *significant from $\mathrm{AD}$ group for unpaired data

\section{Biochemical results:}

The glutamate content in brain tissue homogenates (figure 4):

The glutamate content of the prefrontal cortex and hippocampus were significantly higher in $\mathrm{ACl} 3$-treated rats $(12.5 \pm 2.43$ and $10.5 \pm 1.64)$ as compared to control group $(8.83 \pm 1.47$ and $7.67 \pm 1.3) \mathrm{P}<0.5$ and $\mathrm{P}<0.1$ respectively.

In $\mathrm{AlCl} 3$ treated animals, administration of ARB was associated with significant reduction of glutamate content in the prefrontal cortex $(9.83 \pm 1.17) \mathrm{P}<0.05$ but not in the hippocampus $(9.17 \pm 1.94)$.

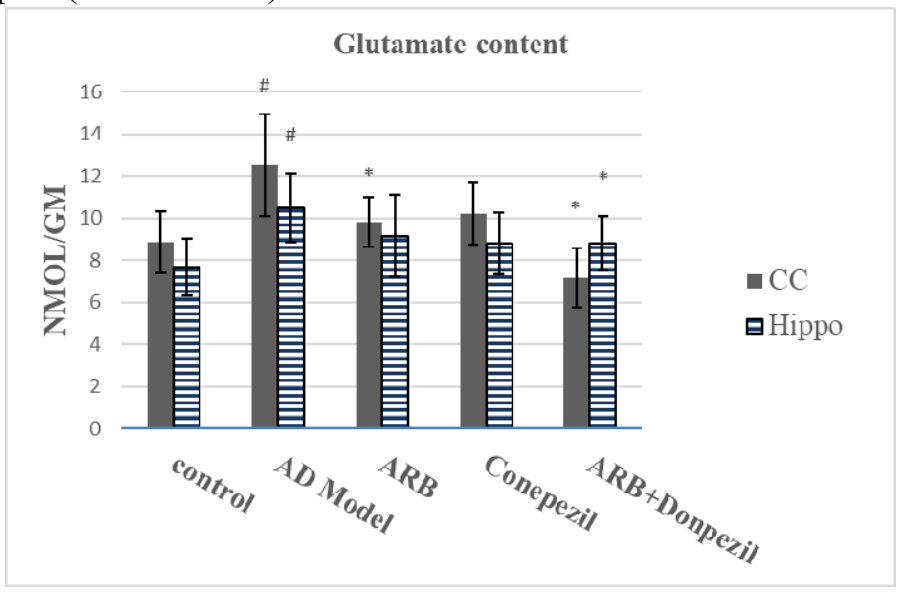

Figure 4: The means and standard deviations of the glutamate content of both the cerebral cortex (CC) and the hippocampus (Hippo) tissue homogenates expressed as means and standard deviations (SD.). ${ }^{\#}$ significant from the control group for unpaired data $\mathrm{P}<0.05$. *significant from $\mathrm{AD}$ group for unpaired data 
MDA content in brain tissue homogenates figure 5:

The MDA content of the prefrontal cortex and hippocampus homogenates were significantly higher in $\mathrm{AlCl} 3$-treated rats $(30.3 \pm 3.33$ and $232 \pm 4.38)$ as compared to control group (10.83 1.47 and $8.5 \pm 1.87) \mathrm{P}$ $<000.1$. In $\mathrm{AlCl} 3$ treated animals, administration of ARB was associated with significant reduction of MDA conternt in the prefrontal cortex $(20.5 \pm 3.02) \mathrm{P}<0.001$, but not in the hippocampus $(23.2 \pm 5.98)$.

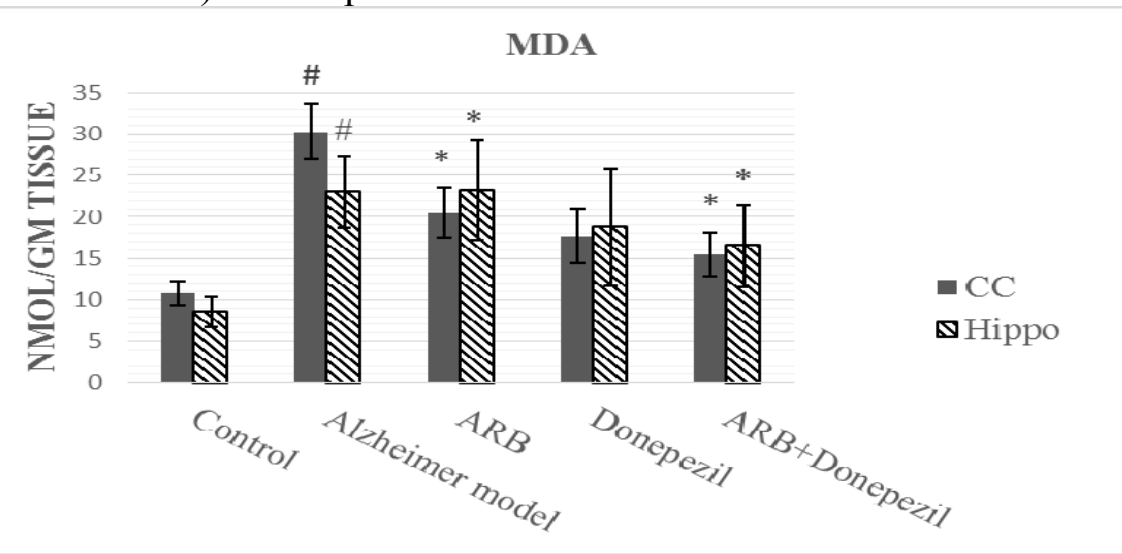

Figure 5: The MDA content of both the cerebral cortex (CC) and the hippocampus (Hippo) tissue homogenates expressed as mean $\pm \mathrm{SD}$. ${ }^{*}$ significant from the control group for unpaired data $\mathrm{P}<0.05$. *significant from $\mathrm{AD}$ group for unpaired data

Similarly, Donepezil administration to $\mathrm{AlCl}_{3}$ injected animals showed significant decrease in MDA content of the prefrontal cortex $(17.7 \pm 3.27) \mathrm{P}<0.001$, but not in the hippocampus $(18.8 \pm 7.08)$. The effect of administration of both donepezil and ARB simultaneously to $\mathrm{AlCl}_{3}$-treated animals was manifested in the form of significant decline of glutamate content in both prefrontal cortex $(12.5 \pm 2.65)$ and the hippocampus $16.5 \pm 4.97, \quad \mathrm{P}<0.001$ and $\mathrm{p}<0.05$ respectively.

GSH content in brain tissue homogenates (figure 6):

The GSH content of the prefrontal cortex and hippocampus homogenates were significantly lower in $\mathrm{AlCl}$-treated rats $(15.3 \pm 3.14$ and $17 \pm 2.61)$ as compared to control group (25.8 \pm 5.42 and $21.5 \pm 3.21) \mathrm{P}$ $<000.1$. In $\mathrm{AlCl}_{3}$-treated animals, administration of $\mathrm{ATR}_{1}$ blocker was associated with significant elevation of GSH content in the prefrontal cortex $(21.7 \pm 3.93)$ $\mathrm{P}<0.05$ and the hippocampus $(20.8 \pm 3.06)$ $\mathrm{P}<05$.

On the contrary, Donepezil administration to $\mathrm{AlCl} 3$ injected animals showed no significant changes in the GSH content of the prefrontal cortex $(20.8 \pm 5.43)$ and the hippocampus $(19.3 \pm 2.07)$. The effect of administration of both donepezil and ARB together to $\mathrm{AlCl}_{3}$-treated animals was associated with significant increase of GSH content in both prefrontal cortex $(28 \pm 5.56)$ and the hippocampus $(22 \pm 3.40) \mathrm{P}<0.05$ for both values. 


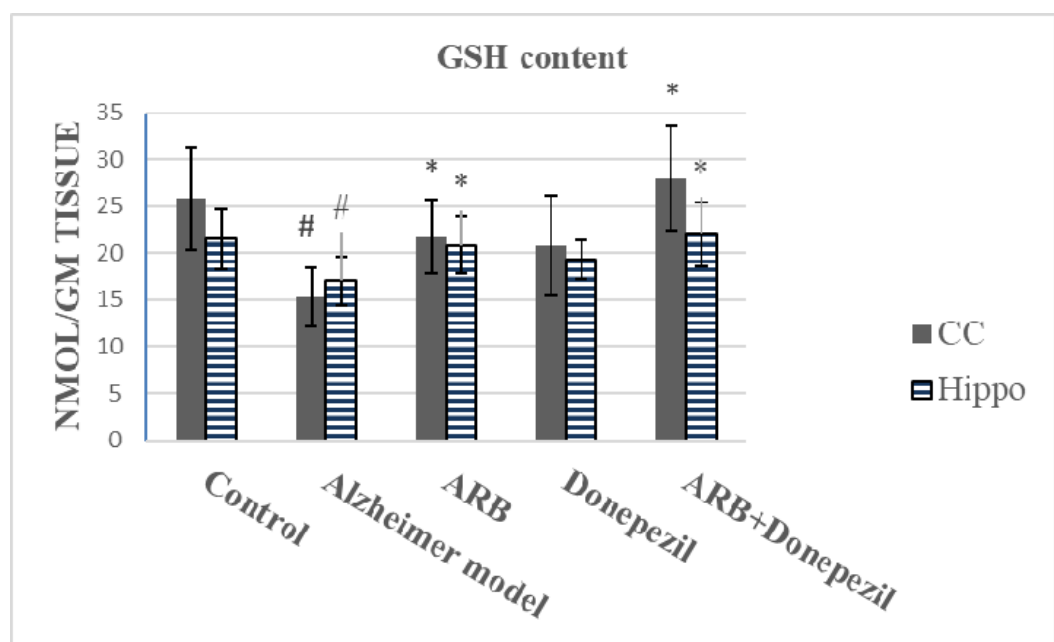

Figure 6: The GSH content of both the cerebral cortex (CC) and the hippocampus (Hippo) tissue homogenates expressed as means \pm SD. ${ }^{\#}$ significant from the control group for unpaired data $P<0.05$. *significant from $A D$ group for unpaired data

\section{DISCUSSION:}

The $\mathrm{AlCl}_{3}$-injected rats showed the features of ATD. Impairment of short-term memory is evidenced by the results of Novel Object Recognition (NOR) test. The data of this group of animals clearly showed significant lowering of DI and RI, higher frequency of exploration for old objects, as well as impairment of locomotor activity. This pattern of memory impairment in our study is previously described in Alzheimer diseases $^{(26 \& 27)}$.

Our data represented other pathological features of $\mathrm{AD}$ in $\mathrm{AlCl}_{3}$-treated rats. Enhanced oxidative stress and high level of lipid peroxidation products with concomitant drop of antioxidant GSH in brain regions presented in this work conform to the results of other investigators ${ }^{(2,5 \& 28)}$. Furthermore, we demonstrated exaggerated glutamate content in both cerebral cortex and hippocampus of rats treated with $\mathrm{AlCl}_{3}$. The result confirms the suggestions that glutamate excitotoxicity is an early feature of $\mathrm{AD}^{(29 \& 30)}$.

The use of $\mathrm{ATR}_{1}$ blocker (telmisartan) four weeks before and during the next four weeks of $\mathrm{AlCl}_{3}$ administration revealed a potential improvement of the induced-ATD. AD group expressed minimal memory impairment through ORT, less accumulation of lipid peroxidation products, higher GSH and lower glutamate contents of cerebral cortex homogenates. Our results show that $\mathrm{ATR}_{1}$ blockade parallel and potentiate the role of the common cholinomimetic agent donepezil, commonly used in treatment of AD.

Improvement of memory function by AT1R blockers was reported by many investigators $^{(9,12)}$. Furthermore, Angiotensin II is reported to inhibit acquisition, consolidation and recall of memory and this inhibition is blocked by AT1R blocker ${ }^{(9 \& 12)}$.

Our results are contradicted however, to the results obtained by Braszko ${ }^{(8)}$, who showed memory improvement by intracerebroventricular (ICV) injection of angiotensin II and this improvement is abolished by $\mathrm{ATR}_{1}$ blocker losartan. This contradiction could be explained by the methodological difference like dose of angiotensin injected, dose and formula of $\mathrm{ATR}_{1}$ blockers used and the test used to examine the memory. 
The memory improvement by $\mathrm{ATR}_{1}$ blocker in our experiment due to blocking the overactivity of RAS components in AD, a finding that is supported by clinical and preclinical studies ${ }^{(15 \& 16)}$. Exaggerated levels of ACE1, angiotensin II and $\mathrm{ATR}_{1}$. in neuro degenerative diseases is recently reported $^{(14 \& 32)}$. RAS overactivity is also a feature of LPS-induced memory impairment in spontaneously hypertensive rats. There are increased levels of angiotensin II, ACE, and $\mathrm{ATR}_{1}$ levels $^{(26)}$. Moreover. AT1R overexpression is a common feature of many brain disorders and a major mechanism of vascular dysfunction ${ }^{(33)}$. There are a strong association between angiotensin II levels and $A \beta$ amyloid and tau protein contents in the brain ${ }^{(14,32)}$. The ICV injection of angiotensin II has a negative impact on memory function ${ }^{(9)}$. The prophylactic effect of $\mathrm{ATR}_{1}$ blocker is a natural consequence due to blocking the deleterious effects of exaggerated angiotensin II. The ATR blockade protects against cellular damage and mitochondrial energy flow ${ }^{(34)}$.

It is worth to say that $\mathrm{ATR}_{2}$ have an opposite role to $\mathrm{ATR}_{1}$ where it protects the brain against oxidative and inflammatory states that characterize $\mathrm{AD}^{(26)}$. Thus, $\mathrm{ATR}_{1}$ blocker produces its positive effect indirectly through increased activity of $\mathrm{ATR}_{2} . \mathrm{ATR}_{2}$ activity directly improves spatial memory in AD mouse model. The $\mathrm{ATR}_{2}$ agonist potentiated memory function and accentuated the excitatory post synaptic potential and neuronal growth in the hippocampus ${ }^{(10)}$. Eventually, the prophylactic effect of $\mathrm{ATR}_{1}$ blocker could be seen in the view of counteraction between the harmful $\mathrm{ATR}_{1}$ and the beneficial $\mathrm{ATR}_{2}$ in the brain. Blocking the $\mathrm{ATR}_{1}$ shifts the balance towards $\mathrm{ATR}_{2}$ which represents the protective axis of the RAS system in the brain $^{(26)}$.

Some authors attribute the beneficial effects of $\mathrm{ATR}_{1}$ blocker at least partly to the blood pressure lowering effect and the increased cerebral blood flow ${ }^{(35)}$. However, the dose and type of $\mathrm{ATR}_{1}$ blocker used in our study is not hypotensive ${ }^{(26)}$.

Our results revealed exaggerated oxidative status. Oxidative stress and impaired energy metabolism have long been associated with pathophysiology of memory impairment ${ }^{(36)}$. It is considered as one of the main pathologic mechanisms of $\mathrm{AD}$ (37). Mitochondrial dysfunction, Abeta amyloid accumulation and inflammation act as different sources of free radical generation in $\mathrm{AlCl}_{3}$-induced brain toxicity ${ }^{(37)}$.

Our results revealed improved oxidative features of rats treated by $\mathrm{ATR}_{1}$ blocker. The significant reduction of lipid peroxidation products and the elevation of the antioxidant GSH may explain the memory protection. Several studies showed that Ang II induces free radicle generation an effect that is mediated by $\mathrm{ATR}_{1}{ }^{(9)}$. The $\mathrm{ATR}_{1}$ blockers oppose this effect ${ }^{(38,39)}$. The antioxidant effect of $\mathrm{ATR}_{1}$ blockade could be attributed to the well-known antioxidant effect of $\mathrm{ATR}_{2}{ }^{(40)}$.

Exaggerated glutamate content is considered an early feature of $\mathrm{ATD}^{(29)}$. Moreover, $\mathrm{AD}$ is associated with disturbed glutamate uptake and hence glutamate excitotoxicity $^{(41)}$. Furthermore, overactivetion of NMDA and AMPA receptors impair memory and learning mechanisms ${ }^{(24) .}$ and act as basis for many neurodegenerative diseases $^{(42)}$.

Finally, the role of $\mathrm{ATR}_{1}$ blockade in ameliorating the excitotoxic effect of excessive glutamate is evident in our study by the decrease glutamate content in brain tissue homogenates in both cerebral cortex and hippocampus. This ability of $\mathrm{ATR}_{1}$ to block glutamate excitotoxicity seems to be a new finding in our study.

In conclusion, our study presented an ATD induced by $\mathrm{AlCl}_{3}$ injections. ATR blockade ameliorated memory function through impairment of oxidative status and 
increasing antioxidant mechanisms in addition to exerting anti-excitotoxic effect. This evidence of beneficial effect of $\mathrm{ATR}_{1}$ blockade would suggest a therapeutic potential in ATD patients.

\section{REFERENCES}

1. Gard P. R. and Rusted J.M. (2001): Angiotensin and Alzheimer disease. therapeutic prospects. Expert. Rev. Neurother. 4: 87-96.

2. Ferreiro E. Baldeiras I., Ferreira I. L., Costa R. O., Rego A. C., Pereira C. F., Oliveira C. R. (2012): Mitochondrialand endoplasmic reticulum-associated oxidative stress in Alzheimer's disease: From pathogenesis to biomarkers, Int. J. Cell. Biol.; 2012: 735206.

3. Butterfield D.A., Swomley A.M. and Sultana R. (2013): Amyloid $\beta$-peptide (142)-induced oxidative stress in Alzheimer disease: Importance in disease pathogenesis and progression. Antioxid. Redox Signal.; 19:823-835.

4. Ansari M.A. and Scheff S.W. (2010): Oxidative stress in the progression of Alzheimer disease in the frontal cortex. J. Neuropathol. Exp. Neurol.; 69:155-167.

5. Padurariu M., Ciobica A., Hritcu L., Stoica B., Bild W. and Stefanescu C. (2010): Changes of some oxidative stress markers in the serum of patients with mild cognitive impairment and Alzheimer's disease. Neurosci Lett.; 18; 469: 6-10.

6. Prakash A., Kalra J., Mani V., Ramasamy K. and Majeed A.B.(2015): Pharmacological approaches for Alzheimer's disease: neurotransmitters as drug targets Expert. Rev. Neurother.; 15: 53-71.

7. Wright J.W. and Harding J.W. (2011): The brain RAS and Alzheimer's disease. Exp Neurol 223: 326-333.

8. Braszko J. J. (2002) AT2 but not AT1 receptor antagonism abolishes angiotensin II increase of the acquisition of conditioned avoidance responses in rats. Behavioural Brain Research; 131: 79-86.

9. Tota S., Goel R., Pachauri S. D., Rajasekar N., Najmi A.K., Hanif K. and Nath C
(2013): Effect of angiotensin II on spatial memory, cerebral blood flow, cholinergic neurotransmission, and brain derived beurotriphic factor in rats. 226(2): 357-69.

10. Jing F., Mogi M., Sakata A., Iwanami J., Tsukuda K., Ohshima K., Min L. J., Steckelings U. M., Unger T., Dahlöf B. and Horiuchi M. (2012): Direct stimulation of angiotensin II type 2 receptor enhances spatial memory. J. Cereb. Blood Flow Metab.; 32: 248-55.

11. Ongali B, Nicolakakis N, Tong $X$. K, Aboulkassim T, Papadopoulos P., RosaNeto P., Lecrux C. Imboden $\mathrm{H}^{3}$, Hamel E (2014): Angiotensin II type 1 receptor blocker losartan prevents and rescues cerebrovascular, neuropathological and cognitive deficits in an Alzheimer's disease model. Neurobiol Dis.; 68:126-36.

12. Kerr D. S., Bevilaqua . LR., Bonini J. S., Rossato J. I., Kohler C. A., Medina J. H., Izquierdo I. and Cammarota M. (2005): Angiotensin II blocks memory consolidation through an AT2 receptor-dependent mechanism. Psychopharmacology (Berl); 179:529-535.

13. Bonini J. S., Bevilaqua L. R., Zinn C. G., Kerr D. S., Medina J. H., Izquierdo I., Cammarota M. (2006): Angiotensin II disrupts inhibitory avoidance memory retrieval. Horm. Behav.; 50: 308-313.

14. Almeida-Santos A. F., Kangussu L. M. and Campagnole-Santos M. J. (2017): The Renin-Angiotensin System and the Neurodegenerative Diseases: A Brief Review. Protein Pept. Lett.; 24(9):841-853

15. Miners S., Ashby E., Baig S., Harrison R., Tayler H., Speedy E. Prince J. A., Love S. and Kehoe P. G. (2009) Angiotensinconverting enzyme levels and activity in Alzheimer's disease: differences in brain and CSFACE and association with ACE1 genotypes. Am. J. Transl. Res. 1:163-177

16. Miners J. S., van Helmond Z., Kehoe P. G. and Love S. (2010): Changes with age in the activities of beta-secretase and the A beta-degrading enzymes neprilysin, insulindegrading enzyme and angiotensin converting enzyme. Brain Pathol.; 20:794802. 
17. Shati A. A., Elsaid F.G., and Hafez E.E. (2011): Biochemical and molecular aspects of aluminium chloride-induced neurotoxicity in mice and the protective role of Crocus sativus L. extraction and honey syrup, Neuroscience; 175: 66-74.

18. Justin Thenmozhi A., William Raja T. R., Manivasagam T., Janakiraman U., Essa M. M. (2017): Hesperidin ameliorates cognitive dysfunction, oxidative stress and apoptosis against aluminium chloride induced rat model of Alzheimer's disease, Nutr Neurosci; 20(6):360-368

19. Li H., Kang T., Qi B., Kong L., Jiao Y., Cao Y., Zhang J. and Yang J. (2016): Neuroprotective effects of ginseng protein on PI3K/Akt signaling pathway in the hippocampus of D-galactose $\mathrm{AlCl} 3$ inducing rats model of Alzheimer's disease, J. Ethnopharmacol.; 179: 162-169.

20. Wienen W., Hauel N., Van Meel J. C., Narr B., Ries U., Entzeroth M.. (2003): Pharmacological characterization of the novel nonpeptide angiotensin II receptor antagonist, BIBR 277. Br. J. Pharmacol.; 110 (1): 245-252.

21. Antunes M. and Biala G. (2012): The novel object recognition memory: neurobiology, test procedure, and its modifications. Cogn. Process.; 13(2): 93-110.

22. Alves N. F., Porpino S. K., Monteiro M. M., Gomes E. R. and Braga V. A. (2015): Coconut oil supplementation and physical esercise improves sensitivity and oxidative stress in hypertensive rats. Appl. Physiol. Nutr. Metab.; 40(4):393-400.

23. Moosavirad S.A., Rabbani M., Sharifzadeh M., Hosseini-Sharifabad A. (2016): Protective effect of vitamin C, vitamin B12 and omega- 3 on leadm induced memory impairment in rat. Res. Pharm. Sci.; 11 (5): 390-396.

24. Hosseini-Sharifabad A., Rabbani M., Sharifzadeh M. and Bagheri N. (2016): Acute and chronic tramadol administration impair spatial memory in rat. Res. Pharm. Sci.; 11 (1):49-57.

25. 25. Engvall E. and Perlmann P. (1971): Enzyme-linked immune-osorbent assay (ELISA) Quantitative assay of immuneglobulin Immunochemistry.; (9):871-874.
26. Goel R., Bhat S. A., Hanif K., Nath C., Shukla R. (2018): Angiotensin II Receptors Blockers Attenuate Lipopolysaccharide Induced Memory Impairment by Modulation of NF- $\kappa \mathrm{B}-$ Mediated BDNF/ CREB Expression and Apoptosis in Spontaneously Hypertensive Rats. Mol. Neurobiol.; 55(2): 1725-1739.

27. Ahmad Rather M; Justin Thenmozhi A, Manivasagam $\mathrm{T}$, Dhivya Bharathi M, Essa M. M. and Guillemin G. (2018): J. Neuroprotective role of Asiatic acid in aluminium chloride induced rat model of Alzheimer's disease. Front Biosci (Schol Ed).; 10: 262-275.

28. Greilberger J., Koidl C., Greilberger M., Lamprecht M., Schroecksnadel K., Leblhuber F., Fuchs D. and Oettl K. (2008): Malondialdehyde, carbonyl proteins and albumin-disulphide as useful oxidative markers in mild cognitive impairment and Alzheimer's disease. Free Radi.c Res; 42 (7), 633-638.

29. Gazulla J. and Cavero-Nagore M. (2006): Glutamate and Alzheimer's disease]. [Article in Spanish]. Rev. Neurol.; 42 (7): 427-32.

30. Hansson O., Zetterberg H., Buchhave P., Londos E., Blennow K.and Minthon L. (2006): Association between CSF biomarkers and incipient Alzheimer's disease in patients with mild cognitive impairment: a follow-up study. Lancet Neurol.; 5(3): 228-234.

31. Braszko J. J. (2005): Valsartan abolishes most of the memory-improving effects of intracerebro-ventricular angiotensin II in rats. Clin. Exp. Hypertens.; 27(8):635-49.

32. Kehoe P. G., Hibbs E., Palmer L. E. and Miners J. S. (2017): Angio- tensin-III is Increased in Alzheimer's Disease in Association with Amyloid- $\beta$ and Tau Pathology. J. Alzheimers Dis.; 58(1):203-214.

33. Saavedra J. M. (2016): Evidence to consider Angiotensin II receptor blockers for the treatment of early Alzheimer's disease, Cell. Mol. Neurobiol.; 36: 259279.

34. Elkahloun A. G., Hafko R. and Saavedra J. M. (2016): An integrative genome-wide transcriptome reveals that candesartan is 
neuroprotective and a candidate therapeutic for Alzheimer's disease. Alzheimers Res. Ther. 8: 5 http://www.ncbi.nlm.nih. gov/ pubmed/ 26822027.

35. Wiesmann M. ${ }^{1}$, Roelofs M., van der Lugt R., Heerschap A., Kiliaan A. J. and Claassen J. A. (2017): Angiotensin II, hypertension and angiotensin II receptor antagonism: Roles in the behavioural and brain pathology of a mouse model of Alzheimer's disease. J. Cereb. Blood Flow Metab.; 37(7):2396-2413.

36. Tota S., Awasthi H., Kamat P. K., Nath C. and Hanif K. (2010): Protective effect of quercetin against intracerebral streptozotocin induced reduction in cerebral blood flow and impairment of memory in in mice. Behav Brain Res. 2010 May 1; 209(1):73-9

37. Vučetić-Arsić S., Radonjić N. V., Jovanović M., Selaković V., Nikolić T., Velimirović M., Stojković T., Milovanović A., Milovanović J. and Petronijević N.D. (2013): Oxidative stress produces mitochondrial dysfunction in gerbil brain after aluminum ingestion. Environ. Toxicol. Pharmacol.; 36(3):1242-52.

38. Jung K. H., Chu K., Lee S. T., Kim S. J., Song E. C., Kim E. H. Park D. K. Sinn D. I. et al. (2007): Blockade of AT1 receptor reduces apoptosis, inflammation, and oxidative stress in normotensive rats with intracerebral hemorrhage. J. Pharmacol. Exp. Ther.; 322:1051-1058

39. Taguchi I., Toyoda S., Takano K., Arikawa T., Kikuchi M., Ogawa M., Abe S., Node K et al (2013): Irbesartan, an angiotensin receptor blocker, exhibits metabolic, antiinflammatory and antioxidative effects in patients with high-risk hypertension. Hypertens. Res.; 36: 608-613.

40. Sabuhi R., Ali Q., Asghar M., Al-Zamily N. R. and Hussain T. (2011): Role of the angiotensin II AT2 receptor in inflammation and oxidative stress: opposing effects in lean and obese Zucker rats. Am. J. Physiol. Renal Physiol.; 300: F700-F706.

41. Matos M., Augusto E., Machado N. J., dos Santos-Rodrigues A., Cunha R. A. and Agostinho P. (2012): Astrocytic adenosine A2A receptors control the amyloid-beta peptide-induced decrease of glutamate uptake, J. Alzheimers Dis.; 31(3): 555-567.

42. Kallarackal A. J., Kvarta M. D., Cammarata E., Jaberi L., Cai X., Bailey A. M. and Thompson S. M. (2013): Chronic stress induces a selective decrease in AMPA receptor-mediated synaptic excitation at hippocampal temporoammonic-CA1 synapses. J. Neurosci.; 33:15669-74 
الدور الفعال لمضادات مستقبلات النجيوتنسين من النوع الثانى فى مرض الالزهايمر فى الفئران د. داطف عبود

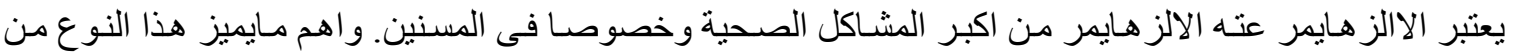

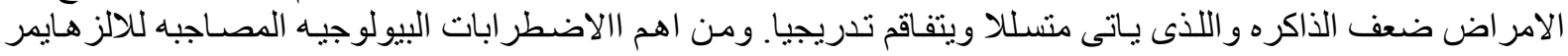

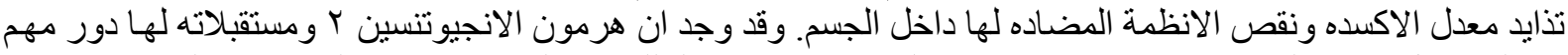

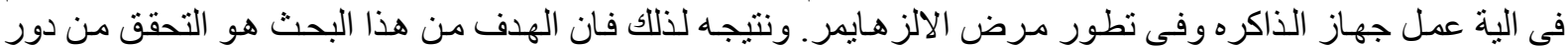

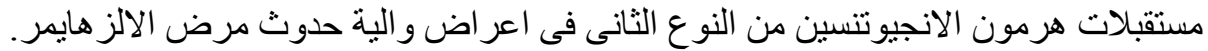

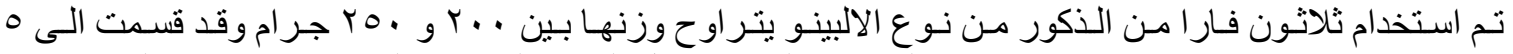

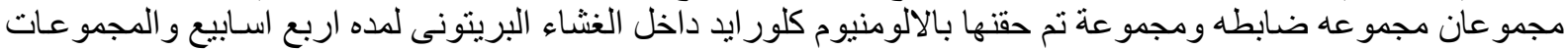

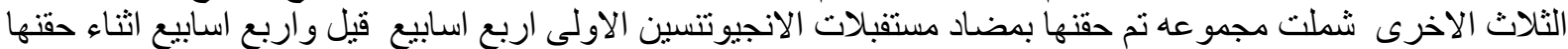

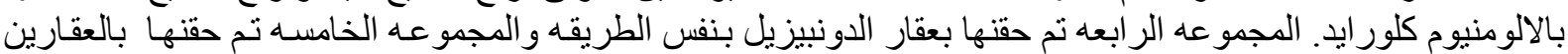

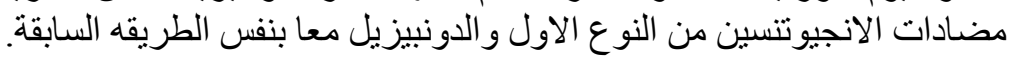

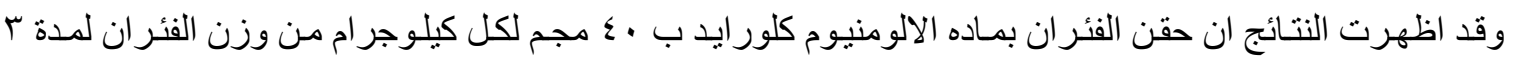

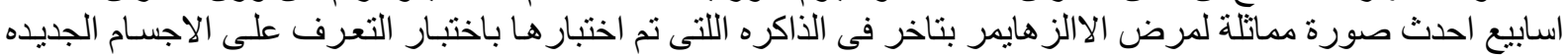

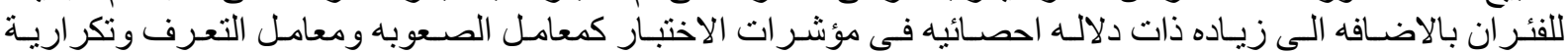

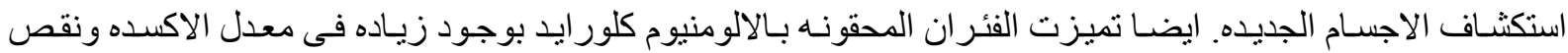

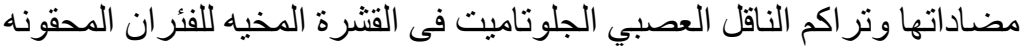

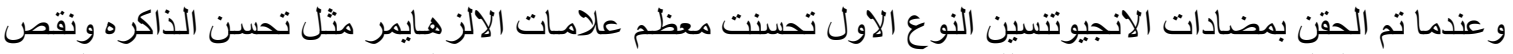

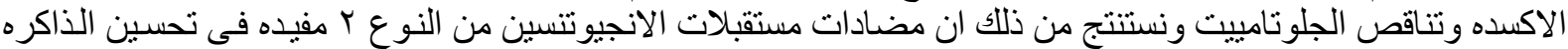
وتخفيف الاكسده ونقص في معدل نر اكم الناقل العصبي الجلوت الناميت 